\title{
THE EFFECTS OF AN INTRAUTERINE DEVICE ON PREGNANCY IN THE GOLDEN HAMSTER
}

\author{
D. W. RICHARDSON AND R. ANSBACHER \\ Center for Research in Reproductive Biology, \\ Department of Obstetrics and Gynecology, University of Michigan Medical Center, \\ Ann Arbor, Michigan 48104, U.S.A.
}

(Received 28th May 1970, revised 9th November 1970)

Summary. The number of conceptuses occurring after placement of an IUD in the right uterine horn of twenty golden hamsters was compared to the number present in ten hamsters subjected to sham operation on Days 7, 12 and 16 of gestation. A unilaterally placed IUD prevented pregnancy in the containing horn, but exerted no significant effect upon implantation sites in the contralateral horn. Sham operations did not prevent implantation.

Histological examination revealed inflammatory reaction only in those uteri containing a silk suture. No communication between uterine lumina could be demonstrated.

The presence of an IUD did not alter the oestrous cycles of hamsters.

\section{INTRODUCTION}

Intrauterine devices (IUDs) manifest their antifertility action through different mechanisms, depending upon the species studied (Marston \& Kelly, 1966; Corfman \& Segal, 1968; Eckstein, 1970).

In the rat, an IUD inserted in one uterine horn exerted a unilateral effect (Doyle \& Margolis, 1964) whereas in the mouse, Doyle \& Margolis (1966) and Bartke (1968) showed that a unilateral IUD prevented pregnancy in the containing horn and reduced the number of conceptuses in the contralateral horn. The device in the hamster prevented pregnancy in the containing horn but did not suppress decidual cell formation (Orsini, 1965).

This study reports the effect of a unilateral IUD on pregnancy in the golden Syrian hamster, Mesocricetus auratus Waterhouse, during various stages of gestation.

\section{MATERIALS AND METHODS}

Thirty, sexually mature, virgin female hamsters were observed daily for three normal oestrous cycles.

Twenty hamsters were fitted with an IUD in the right uterine horn only. A 
2-0 black silk suture was placed into the right uterine lumen with a straight $2-\mathrm{cm}$ atraumatic needle. The IUD was inserted $0.5 \mathrm{~cm}$ proximal to the uterocervical junction and was anchored externally with a double knot on the antimesometrial surface $0.5 \mathrm{~cm}$ distal to the utero-tubal junction.

A sham operation was performed on the left uterine horn in similar fashion, but the silk suture was removed after being threaded through the length of the lumen. Sham operations were performed on both uterine horns of ten hamsters, which served as controls.

All the hamsters were observed daily postoperatively for three cycles to determine the effect of the IUD and the sham operation on subsequent cycling. The animals were mated with fertile males, and the presence of a copulation plug or intravaginal spermatozoa was taken to indicate Day 1 of pregnancy.

The litter size in this strain of hamsters varies from one to twelve, with a modal number of six or seven. Implantation occurs on Day 4 of pregnancy and the length of gestation is usually 16 days (Asdell, 1964).

Exploratory laparotomy was performed on Days 7, 12 and 16 of pregnancy to correlate the effects of the IUD at various stages of gestation. The number of normal and resorbing conceptuses in each uterine horn was counted, and the presence of corpora lutea and the position of the IUD were verified.

Before surgery, the hamsters were anaesthetized with intraperitoneal pentobarbital sodium $(8 \mathrm{mg} / 100 \mathrm{~g}$ body weight). The operations were performed under clean but not sterile conditions.

The results were evaluated either with the $t$ test or by analysis of variance.

Representative uteri were submitted for histological examination.

\section{RESULTS}

Normal oestrous cycles occurred in all the hamsters both after placement of the IUD and after sham operation.

The comparison of the number of conceptuses on Days 7, 12 and 16 of gestation in the control and the IUD groups is given in Table 1.

No differences occurred in the control group between the number of conceptuses in the right and the left uterine horns at any stage of gestation. A significant reduction in the number of normal conceptuses between Days 7 and 16 $(P<0.01)$ and between Days 12 and $16(P<0.01)$ was noted, with an increase in resorbing conceptuses by Day 16.

The IUD prevented pregnancy in the right uterine horn but not in the contralateral horn (see Plate 1). In two hamsters, however, four conceptuses were present in the IUD horn. This was probably due to a short intrauterine suture. In the contralateral horn subjected to sham operation, there was a significant decrease of normal conceptuses throughout gestation $(P<0.01)$. As in the control group, the number of resorbing sites increased throughout gestation.

There were no significant differences in the total number, normal, or resorbing conceptuses between the left horns of control hamsters and the left horns of animals with the IUD in situ. 
PI.ATE 1

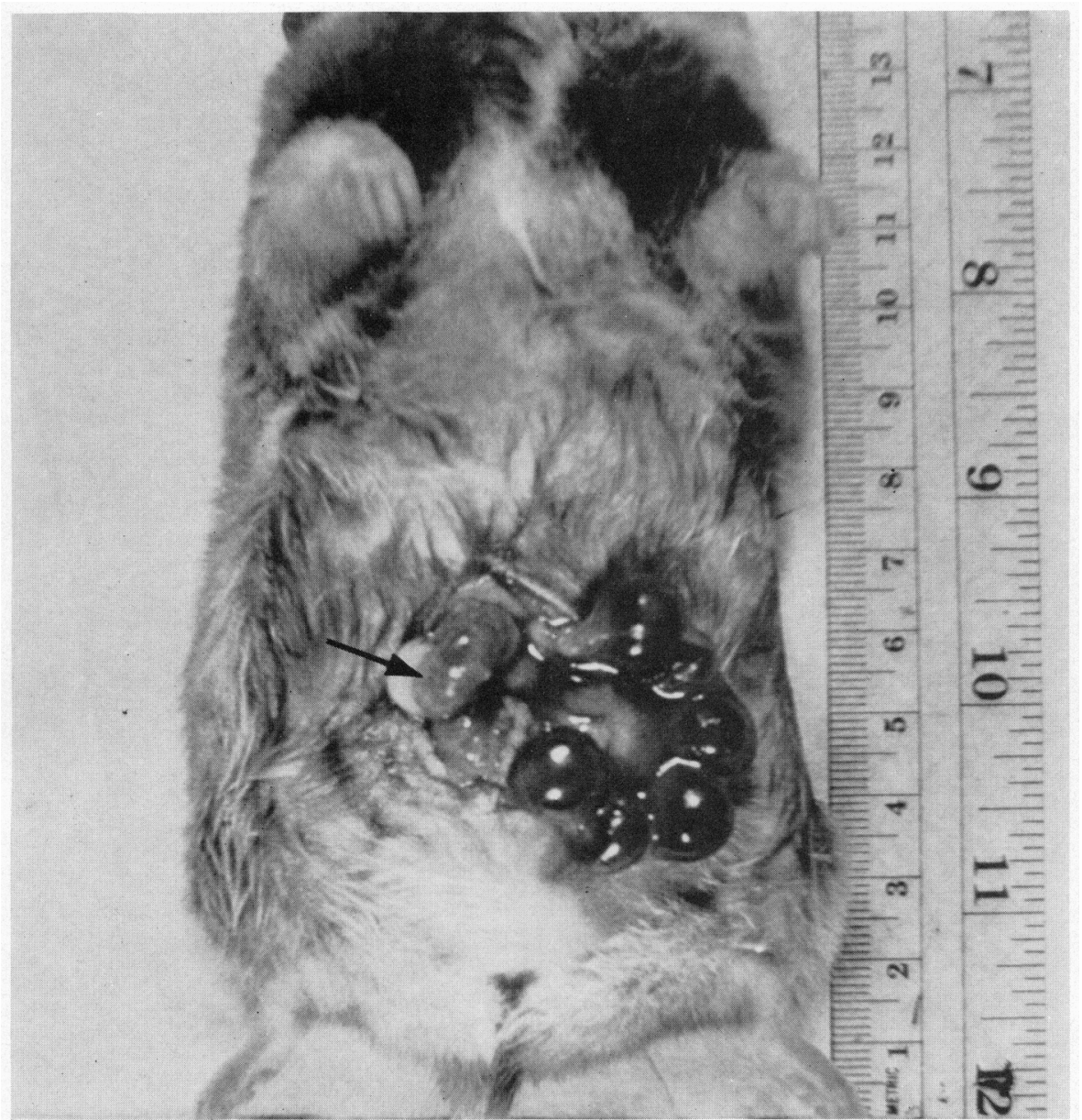

Hamster on Day 12 of pregnancy with an IUD in the right uterine horn (arrowed) and normal conceptuses in the left uterine horn which was subjected to sham operation. The right uterine horn shows slight hypertrophy. 


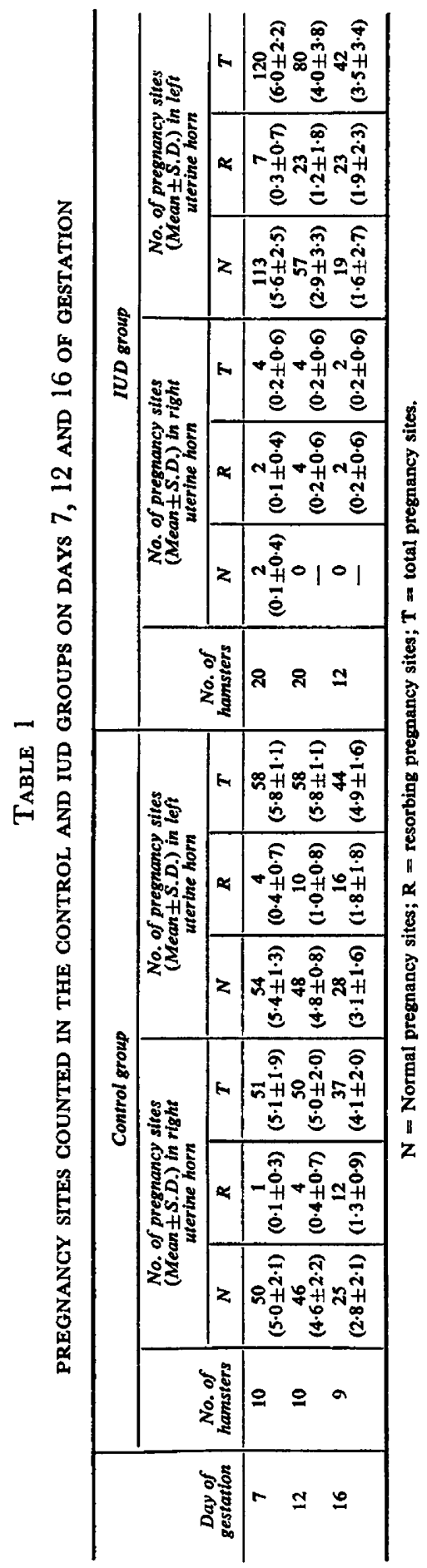




\section{DISCUSSION}

The IUD prevented pregnancy in the containing horn, as was reported by Orsini (1965), but did not prevent implantation in the contralateral horn of the hamster. The sham operation did not prevent implantation, an observation previously reported in rats (Chaudhury \& Tarak, 1965), and the implantation rate was equal in both the control and the IUD groups.

A loss of forty implantation sites, probably due to rapid resorption between Days 7 and 12, was noted in the IUD group, without a comparable finding in the control group.

The presence of the IUD did not alter the length of the hamster's oestrous cycle, confirming the finding of Orsini (1965) in the hamster, and those of Schuchner \& Davidson (1964) in rats.

The IUD horns were dilated and hypertrophied as compared to the horns subjected to sham operation, and myometrial hypertrophy was evident on histological study, but these changes were not seen in the uteri subjected to sham operation. Similar findings were reported by Parr \& Segal (1966) in the rat, and by Ledger \& Bickley (1966) in the rabbit.

Only in uteri containing a silk suture were inflammatory reactions noted, which were characterized by the presence of a polymorphonuclear infiltration mainly in the endometrium but also in the myometrium. This was not present in the contralateral horns. Similar inflammatory reactions were observed with the presence of the IUD in rats (Greenwald, 1965), rats, germ-free rats, rabbits and mice (Parr, Schaedler \& Hirsch, 1967); rabbits (Marston \& Chang, 1969) and germ-free and conventional rats (Parr, 1969).

The mechanism by which the IUD inhibits implantation in the uterine horn is still obscure. In hamsters, normal decidual cell formation occurs (Orsini, 1965), whereas in rats (Margolis \& Doyle, 1964; Marston \& Chang, 1964) and in mice (Bartke, 1968), interference with the normal decidual reaction was noted.

A bilateral effect, suggesting a possible humoral factor, was observed after placement of a unilateral IUD in mice (Doyle \& Margolis, 1966) since a communication does exist between the two horns. Serial sectioning failed to demonstrate a communication between the uterine lumina in the hamster in any of the specimens examined, verifying a suggestion made by Orsini (personal communication, 1969).

A local effect of the silk suture on the uterine horn appears to be implicated but further studies are needed to ascertain the exact mechanism of action.

\section{ACKNOWLEDGMENTS}

This work was supported by a research grant, No. 37482, from the Ford Foundation. The authors wish to thank Dr Leigh S. Whitlock for his help in the statistical analysis of the data and Dr Gerald D. Abrams for his assistance in examining the histological material.

\section{REFERENCES}

Asdeli, S. A. (1964) Patterns of mammalian reproduction, 2nd edn, p. 282. Comstock Publishing Company, Cornell University Press, Ithaca, New York. 
BARTKE, A. (1968) Effect of an IUD on implantation and the decidual reaction in different strains of mice. F. Reprod. Fert. 15, 185.

GhaudhURY, R. R. \& TARAK, T. K. (1965) Effect of intrauterine silk thread suture on fertility of female rats. Br. med. J. i, 31 .

Corrman, P. A. \& SEgal, S. J. (1968) Biologic effects of intrauterine devices. Am. J. Obstet. Gynec. 100, 448.

DoyLe, L. L. \& MARgolis, A. J. (1964) Intra-uterine foreign body studies in rodents. Proc. 2nd int. Conf. on Intra-uterine Contraception. Excerpta med. Int. Congr. Ser. 86, 185.

Doyle, L. L. \& Margolis, A. J. (1966) The effect of an IUFB on reproduction in mice. F. Reprod. Fert. 11, 27.

Eckstern, P. (1970) Mechanisms of action of intra-uterine contraceptive devices in women and other mammals. Br. med. Bull. 26, 52.

GREenWALd, G. S. (1965) Interruption of pregnancy in the rat by a uterine suture. F. Reprod. Fert. 9, 9.

LEDGER, W. J. \& BICKLEY, J. E. (1966) Effect of a plastic foreign body on the genital tract of the female rabbit. Obstet. Gynec. N.Y. 27, 658.

Margolis, A. J. \& Doyle, L. L. (1964) Intrauterine foreign body. II. Inhibition of decidual response in the rat. Fert. Steril. 15, 607.

Marston, J. H. \& Chang, M. C. (1964) Action of intra-uterine foreign bodies in the rat and rabbit. Proc. 2nd int. Conf. on Intra-uterine Contraception. Excerpta med. Int. Congr. Ser. 86, 242.

Marston, J. H. \& Chang, M. C. (1969) Contraceptive action of intra-uterine devices in the rabbit. $\mathcal{F}$. Reprod. Fert. 18, 409.

Marston, J. H. \& KelLy, W. A. (1966) The effects and mode of action of intrauterine devices. Vet. Rec. 79, 644 .

Orsint, M. W. (1965) Effect of an intrauterine foreign body on the cycle and pregnancy in the hamster, Mesocricetus auratus Waterhouse. Anat. Rec. 151, 468.

PARR, E. L. (1969) The role of inflammation in the uterine weight increase caused by an IUD. $\mathcal{F}$. Reprod. Fert. 18, 221.

Parr, E. L., Schaedler, R. W. \& Hirsch, J. G. (1967) The relationship of polymorphonuclear leukocytes to infertility in uteri containing foreign bodies. F. exp. Med. 126, 523.

PARR, E. L. \& SEgaL, S. J. (1966) The effect of an intrauterine contraceptive device on the weight of the rat uterus. Fert. Steril. 17, 648.

Schuchner, E. B. \& Davidson, O. W. (1964) Effect on rat pregnancy of an intra-uterine silk thread. Proc. 2nd int. Conf. on Intra-uterine Contraception. Excerpta med. Int. Congr. Ser. 86, 248. 